\title{
Does Soil Organic Matter Affect the Impact of the Ionic Liquid Ethylammonium Nitrate in the Pure State and as Mixture with Lithium Salt on Basal Soil Respiration? ${ }^{\dagger}$
}

\author{
Teresa Sixto ${ }^{1}$, María Eugenia Priano ${ }^{1,2}$, Otilia Reyes ${ }^{3}$, Juan José Parajó ${ }^{4,5}$, Josefa Salgado ${ }^{4}$ and \\ Carmen Trasar-Cepeda ${ }^{1, *}$
}

Citation: Sixto, T.; Priano, E.; Reyes, O.; Parajó, J.J.; Salgado, J.;

Trasar-Cepeda, C. Does soil Organic Matter Affect the Impact of the Ionic Liquid Ethylammonium Nitrate in the Pure State and as Mixture with Lithium Salt on Basal Soil

Respiration? Chem. Proc. 2021, 3, 93 . https://doi.org/10.3390/ecsoc-2408376

Academic Editors: Julio A. Seijas and M. Pilar Vázquez-Tato

Published: 14 November 2020

Publisher's Note: MDPI stays neutral with regard to jurisdictional claims in published maps and institutional affiliations.

Copyright: $\odot 2020$ by the authors. Licensee MDPI, Basel, Switzerland. This article is an open access article distributed under the terms and conditions of the Creative Commons Attribution (CC BY) license (http://creativecommons.org/licenses/by/4.0/).
1 Departamento de Bioquímica del Suelo, Instituto de Investigaciones Agrobiológicas de Galicia (CSIC), 15705 Santiago de Compostela, Spain; tere.sixto@gmail.com (T.S.); marupriano@gmail.com (M.E.P.)

2 CIFICEN, Universidad Nacional del Centro de la Provincia de Buenos Aires, 7000 Tandil, Argentina

3 BIOAPLIC Group, Departamento de Bioloxía Funcional, Universidade de Santiago de Compostela, 15705 Santiago de Compostela, Spain; otilia.reyes@usc.es

4 NaFoMAT Group, Departamento de Física Aplicada, Universidade de Santiago de Compostela, 15705 Santiago de Compostela, Spain; juanjose.parajo@usc.es (J.J.P.); j.salgado.carballo@usc.es (J.S.)

5 CIQUP-Centro de Investigaçao em Química da Universidade do Porto, Universidade do Porto, 4169-007 Porto, Portugal

* Correspondence: ctrasar@iiag.csic.es; Tel.: +34-981-590-958 (ext. 270)

+ Presented at the 24th International Electronic Conference on Synthetic Organic Chemistry, 15 November-15 December 2020; Available online: https://ecsoc-24.sciforum.net/.

\begin{abstract}
Although ionic liquids (ILs) do not contaminate the atmosphere (because of their low vapour pressure), they may have toxic effects in aquatic and terrestrial environments. Therefore, before ILs can be widely used for different applications, their toxicity must be tested in different environments. The IL ethylammonium nitrate (EAN) is of interest in electrochemical applications, and research is currently underway to investigate the electrochemical activity of mixtures of this compound with inorganic salts. In this study, we investigated the impacts of different amounts of pure EAN and of mixtures of EAN and lithium salt on basal soil respiration in two soils differing in organic matter content.
\end{abstract}

Keywords: ionic liquids; ethylammonium nitrate; lithium nitrate; electrolyte; basal soil respiration; ecotoxicity; soil pollution

\section{Introduction}

Ionic liquids (ILs) have exceptional thermophysical properties that make them very attractive as solvents for different applications, e.g., as electrolytes in high-voltage batteries, advanced supercapacitors and next-generation fuel cells (because of the wide electrochemical window and high levels of ionic conductivity and chemical and thermal stability). In addition, the negligible vapour pressure of ILs prevents them from contaminating the atmosphere and constitutes a further advantage for their use as an alternative to conventional volatile organic solvents [1]. Nevertheless, this does not imply that ILs are not toxic to aquatic or terrestrial environments, and this possibility must be investigated in depth [2-4]. Some ILs are soluble in water, and could therefore easily reach aquatic or terrestrial ecosystems in the case of an accidental spill or leakage from storage sites. One water-soluble IL, ethylammonium nitrate, has recently been assessed for use in diverse applications (as an electrolyte, additive, detergent and precipitating agent [5-7]). Particular interest has been shown in relation to the electrochemical activity of mixtures of this $\mathrm{IL}$ and different inorganic salts (such as $\mathrm{Li}, \mathrm{Mg}, \mathrm{Ca}$ and $\mathrm{Al}$ salts) and the use of the mixtures as electrolytes in high-voltage batteries [7]. 
As soil is a non-renewable resource, at least within the human lifespan [8], preservation of soil quality is fundamental for environmental conservation [9]. Among the various different soil properties, those determining edaphic metabolism and especially the soil biochemical properties (e.g., basal soil respiration, nitrogen mineralisation, soil microbial biomass and enzyme activities) are highly sensitive to disturbance by external agents [1012]. Moreover, soils with different characteristics, especially in relation to organic matter content and $\mathrm{pH}$, may react differently to the presence of exogenous compounds [13]. Therefore, the toxicity of ILs in soils with different characteristics must be established, as this can affect the impact that different ILs may have on soil functioning.

This study aimed to assess the toxicity of the IL ethylammonium nitrate (EAN) and of mixtures of EAN and lithium nitrate salt (EAN-Li) by evaluating the impact of different amounts of these materials on basal soil respiration and respiration kinetics, in two soils of similar texture and $\mathrm{pH}$, but differing in organic matter content.

\section{Materials and Methods}

\subsection{Chemicals}

The IL ethylammonium nitrate (EAN) (97\% pure, analytical grade) was purchased from IOLITEC (Heilbronn, Germany). The lithium nitrate $\left(\mathrm{LiNO}_{3}\right)$ salt was obtained from Sigma-Aldrich. The main chemical and structural characteristics of these compounds are summarized in Table 1. The IL was further purified in a high vacuum device until the water content fell below 100 ppm.

Table 1. Main characteristics of the ionic liquid ethylammonium nitrate and of lithium nitrate.

\begin{tabular}{ccccc}
\hline Name & $\begin{array}{c}\text { Abbreviation } \\
\text { [CAS Number] }\end{array}$ & Structure & Mw (g/mol) & $\begin{array}{c}\text { Purity (\%) } \\
\text { (Provenance) }\end{array}$ \\
\hline Ethylammonium nitrate & $\begin{array}{c}\text { EAN } \\
{[22113-86-6]}\end{array}$ & 108.097 & $\begin{array}{c}>97.00 \\
(\text { Iolitec) }\end{array}$ \\
\hline Lithium nitrate & LiNO3 & 68.946 & 99.99 \\
(Sigma-Aldrich)
\end{tabular}

A saturated solution of EAN and $\mathrm{LiNO}_{3}(\mathrm{EAN}-\mathrm{Li})$ was obtained by mixing both components at room temperature for 24 to $48 \mathrm{~h}$, in an ultrasound bath when needed, by increasing molality in $0.5 \mathrm{~mol} \mathrm{~kg}^{-1}$ intervals until saturation point was reached [7].

\subsection{Soils and Soil Collection Procedure}

A forest soil developed under oakwood vegetation (Negreira soil) and an agricultural soil under maize cultivation (A Pedra soil) were selected for the study. The forest soil was an Umbrisol, while the agricultural soil was a Regosol [14]. Both were developed over granite rock. Between 10 and 15 subsamples of the A horizon $(0-10 \mathrm{~cm})$ of each soil were obtained, after removing the litter layer (forest soil) and the plant remains (agricultural soil). The subsamples were pooled in the field to produce a composite sample for each site. The soil samples were transported in isothermal bags to the laboratory where they were sieved $(<4 \mathrm{~mm})$. A sub-sample of each soil was air-dried for determination of general soil properties, and the remainder was stored at $4{ }^{\circ} \mathrm{C}$ until the beginning of the experiment.

The soils were acid, with a sandy-loam texture and with very different organic matter contents. Thus, the agricultural soil was characterised by a total C content of $2.17 \%$ and a total $\mathrm{N}$ content of $0.21 \%$, while the forest soil was characterised by a total C content of $12.43 \%$ and a total $\mathrm{N}$ content of $0.65 \%$ (Table 2 ). (See below for methods used to determine the soil properties). 
Table 2. Main characteristics of the soils used in the study. Mean values \pm standard deviations.

\begin{tabular}{|c|c|c|c|c|c|c|c|c|c|}
\hline \multirow[t]{2}{*}{ Soil } & pH KCl & $\mathrm{Ct}$ & $\mathrm{Nt}$ & $\mathrm{C} / \mathrm{N}$ & Sand & Silt & Clay & Texture & $\begin{array}{c}\text { Field Water Capacity } \\
(\%)\end{array}$ \\
\hline & \multicolumn{4}{|c|}{-------- \% -------- } & \multicolumn{3}{|c|}{-------- \% --------- } & & \\
\hline Negreira & $3.28 \pm 0.01$ & $12.43 \pm 0.06$ & $0.65 \pm 0.00$ & 19 & 71 & 16 & 13 & Sandy loam & 85.0 \\
\hline A Pedra & $3.67 \pm 0.02$ & $2.17 \pm 0.05$ & $0.21 \pm 0.02$ & 10 & 66 & 23 & 11 & Sandy loam & 34.2 \\
\hline
\end{tabular}

\subsection{Experimental Set-Up}

Different solutions of EAN and EAN-Li were prepared by diluting each in distilled water, to yield final concentrations of $0,1,10,25,50,75$ and 100\%. The moisture content of sieved soils was pre-adjusted to the required level of soil moisture, so that after addition of the IL solution, the moisture content was $80 \%$ of the soil field water capacity (Table 2). The soils were then spiked with $0.1 \mathrm{~mL}$ of the EAN or EAN-Li solution per gram of soil (equivalent to doses of $0,1.75,17.47,43.68,69.90,104.84$ and $123.48 \mathrm{~g}$ of EAN or EAN-Li $\mathrm{kg}^{-1}$ air-dried soil) and maintained at $20^{\circ} \mathrm{C}$ for three days to maximize contact between the soil and the IL. This contact time was selected on the basis of the results of prior experiments that indicated that the major modifications in soil properties occur within $72 \mathrm{~h}$ of contamination $[4,15,16]$. Three days after the IL was added to the soil, all of the EAN and EAN-Li spiked soil samples were incubated at $25{ }^{\circ} \mathrm{C}$ and $80 \%$ field water retention capacity and basal soil respiration and respiration kinetics were measured.

\subsection{Analytical Methods}

Basal soil respiration was determined in triplicate by static incubation [17]. Briefly, equivalent amounts to $25 \mathrm{~g}$ of moist soil samples were incubated in tightly closed Mason jars at $80 \%$ field moisture content and at $25^{\circ} \mathrm{C}$ (optimal conditions) for 10 days. The $\mathrm{CO}_{2}$ produced was collected in $10 \mathrm{~mL}$ of a $1 \mathrm{M} \mathrm{NaOH}$ solution, which was then titrated against $\mathrm{HCl}$ with an automatic titrator. Two Mason jars with $\mathrm{NaOH}$ solution but no soil were also incubated under the same conditions to take into account the $\mathrm{CO}_{2}$ in the jars. To estimate the kinetics of soil respiration, the $\mathrm{NaOH}$ solution was collected and titrated after 1, 2, 4, 7 and 10 days. On each occasion, the jars were left open for $30 \mathrm{~min}$ to allow replacement of the air before fresh $\mathrm{NaOH}$ solution was added. However, for the IL-contaminated soils, the 10-day incubation period proved too short and had to be increased until the $\mathrm{CO}_{2}$ emitted by soil respiration in IL-spiked soils stabilised or had reached the same level as in the control, un-spiked soil. The incubation time varied depending on the soil, the solution applied (EAN or EAN-Li) and the amount of IL applied to the soil. The $\mathrm{NaOH}$ was replaced after 1, 2, 4, 7, 10 and 14 days and every week thereafter. The volume and molarity of the $\mathrm{NaOH}$ was modified each time, depending on the evolution of the $\mathrm{CO}_{2}$ emitted by the soils, to ensure that there was sufficient $\mathrm{NaOH}$ to retain the $\mathrm{CO}_{2}$ emitted by the control and the IL-spiked soils.

The main physical and chemical properties of the soils were determined in air-dried sub-samples. Total $\mathrm{C}$ and $\mathrm{N}$ contents of finely ground samples were determined in a $\mathrm{C}$, $\mathrm{N}$, H Elemental Analyser (LECO Instruments S.L.); soil pH was determined in a suspension in $1 \mathrm{M} \mathrm{KCl}$ (1:2.5 soil:solution ratio) as described by Guitián-Ojea and Carballas-Fernández [17]. Particle size distribution was determined using a Robinson pipette with Calgon as dispersant [17], and the textural class was assigned according to the USDA soil texture classification [18]. Field water capacity was determined as the water retained by the soil at a potential of $-30.4 \mathrm{kPa}$, which was measured in undisturbed soil samples with a Richards plate-and-membrane apparatus [17]. The soil moisture content was determined after oven-drying the soil at $105^{\circ} \mathrm{C}$ for $24 \mathrm{~h}$. 


\section{Results and Discussion}

As previously indicated, the duration of the incubation period was different for the two soils and the ILs, except in the A Pedra soil spiked with EAN-Li (for which the incubation time was 21 days in all spiked and un-spiked samples); it also differed between IL doses (although in the case of the A Pedra soil spiked with EAN only, the soil spiked with $104.84 \mathrm{~g} \mathrm{EAN} \mathrm{kg}^{-1}$ soil had to be incubated longer than the other samples, both spiked and un-spiked) (Figures 1 and 2).

As expected, basal soil respiration was highest in the soil with the highest organic matter content (Negreira soil). In both soils, the lowest dose of EAN and EAN-Li did not affect soil respiration, and the total amounts of $\mathrm{CO}_{2}-\mathrm{C}$ emitted by the soils spiked with $1.75 \mathrm{~g}$ EAN or EAN-Li kg-1 soil were almost the same as those emitted by the corresponding control (un-spiked) soil (Figures 1 and 2). However, all the other doses of IL strongly affected soil respiration, and the effect differed depending on the soil and the IL considered.

In the Negreira soil, the application of both EAN and EAN-Li caused a very large increase in the total amount of $\mathrm{CO}_{2}-\mathrm{C}$ emitted during the incubation period, and the increase in the amount of $\mathrm{CO}_{2}$ emitted increased with the amount of IL added to the soil. Similarly, in the A Pedra soil spiked with EAN, the total amount of $\mathrm{CO}_{2}$ emitted during the incubation increased relative to that of the un-spiked soil, and in this case the amount of $\mathrm{CO}_{2}$ emitted also increased with the amount of EAN added to the soil. The very high total amount of $\mathrm{CO}_{2}$ emitted by the A Pedra soil spiked with $104.84 \mathrm{~g}^{\mathrm{EAN} \mathrm{kg}}{ }^{-1}$ soil was remarkable; unlike in all the other IL-spiked and non-spiked soils, the level did not reach a plateau, but continued to increase even after 197 days of incubation (Figure 2). The behaviour of the A Pedra soil spiked with EAN-Li differed from that of the other IL-spiked soils (Negreira+EAN, Negreira+EAN-Li and A Pedra+ EAN). Thus, the total $\mathrm{CO}_{2}$ emitted only increased in the soil spiked with 17.47 and $43.68 \mathrm{~g} \mathrm{EAN-Li} \mathrm{kg}^{-1}$ soil (Figure 1), while in the soil spiked with higher amounts of EAN-Li the total amount of $\mathrm{CO}_{2}$ emitted during the incubation decreased relative to that emitted by the control soil, and the decrease increased gradually with the amount of IL applied to the soil $(98,70$ and $45 \mathrm{mg} \mathrm{CO}-\mathrm{C}$ emit-

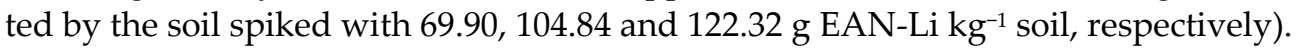
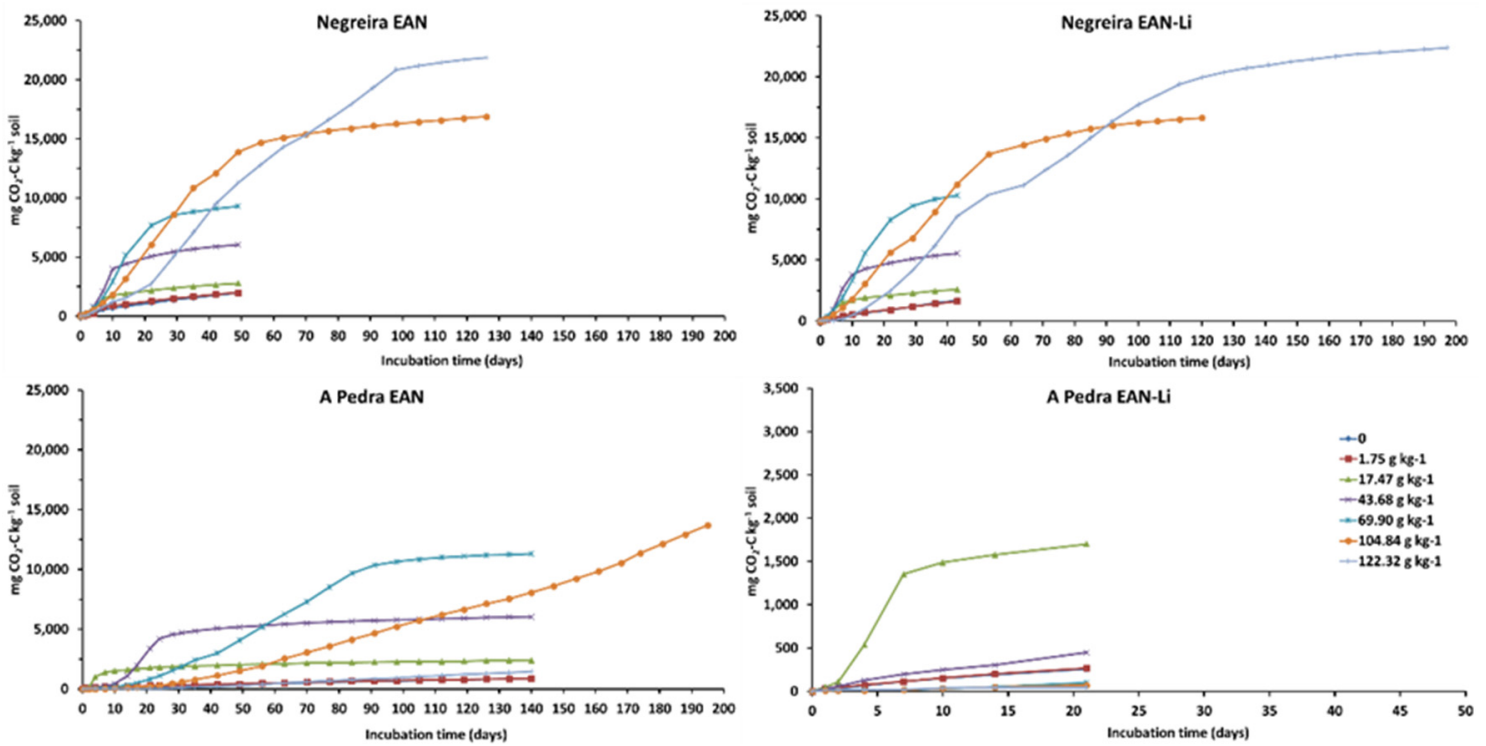

Figure 1. Cumulative $\mathrm{CO}_{2}-\mathrm{C}$ emitted by un-spiked Negreira (left) and A Pedra (right) soils and the same soils spiked with different amounts of ethylammonium nitrate (EAN) alone (above) or mixed with lithium nitrate salt (EAN-Li) (below). Note that the limits in $\mathrm{Y}$ and $\mathrm{X}$ axes in A Pedra soil spiked with EAN-Li are lower than in the other cases.

In addition to changes in the amount of $\mathrm{CO}_{2}$, the kinetics of the $\mathrm{CO}_{2}$ emission were also modified by the application of EAN and EAN-Li to the soils. In all cases, and as usually observed when soil is incubated at optimal conditions of temperature and moisture, 
a peak in $\mathrm{CO}_{2}$ emission occurred. However, while this peak occurred shortly after the beginning of the incubation (1 to 7 days) in un-spiked soils and in the soils spiked with the lowest amount of EAN and EAN-Li ( $1.75 \mathrm{~g} \mathrm{~kg}^{-1}$ soil), the timing of the peak was gradually delayed as the dose of IL increased in both types of soil. Thus, in the Negreira soil this occurred both in EAN and in EAN-Li-spiked soils and for all the doses of IL, while in the A Pedra soil it only occurred in the EAN-spiked soil, as in the A Pedra soil spiked with EAN-Li, and as already indicated, only the 17.47 and 43.68 doses of EAN-Li caused an increase in the amount of $\mathrm{CO}_{2}$ emitted. Moreover, in the A Pedra soil spiked with $17.47 \mathrm{~g}$ EAN-Li kg-1 the peak was almost unappreciable. The kinetics of $\mathrm{CO}_{2}$ emission in the A Pedra soil spiked with EAN were also remarkable. The peak was very clear only for EAN-

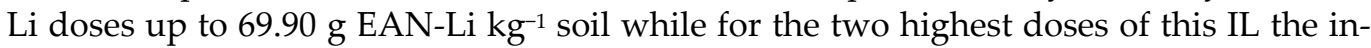
creased emission of $\mathrm{CO}_{2}$ was maintained for a long period of time, from 21 to 91 days of incubation in the soil spiked with $104.84 \mathrm{~g} \mathrm{~kg}^{-1}$ of EAN and from day 21 until the end of the incubation (197 days) in the soil spiked with the highest amount of EAN.
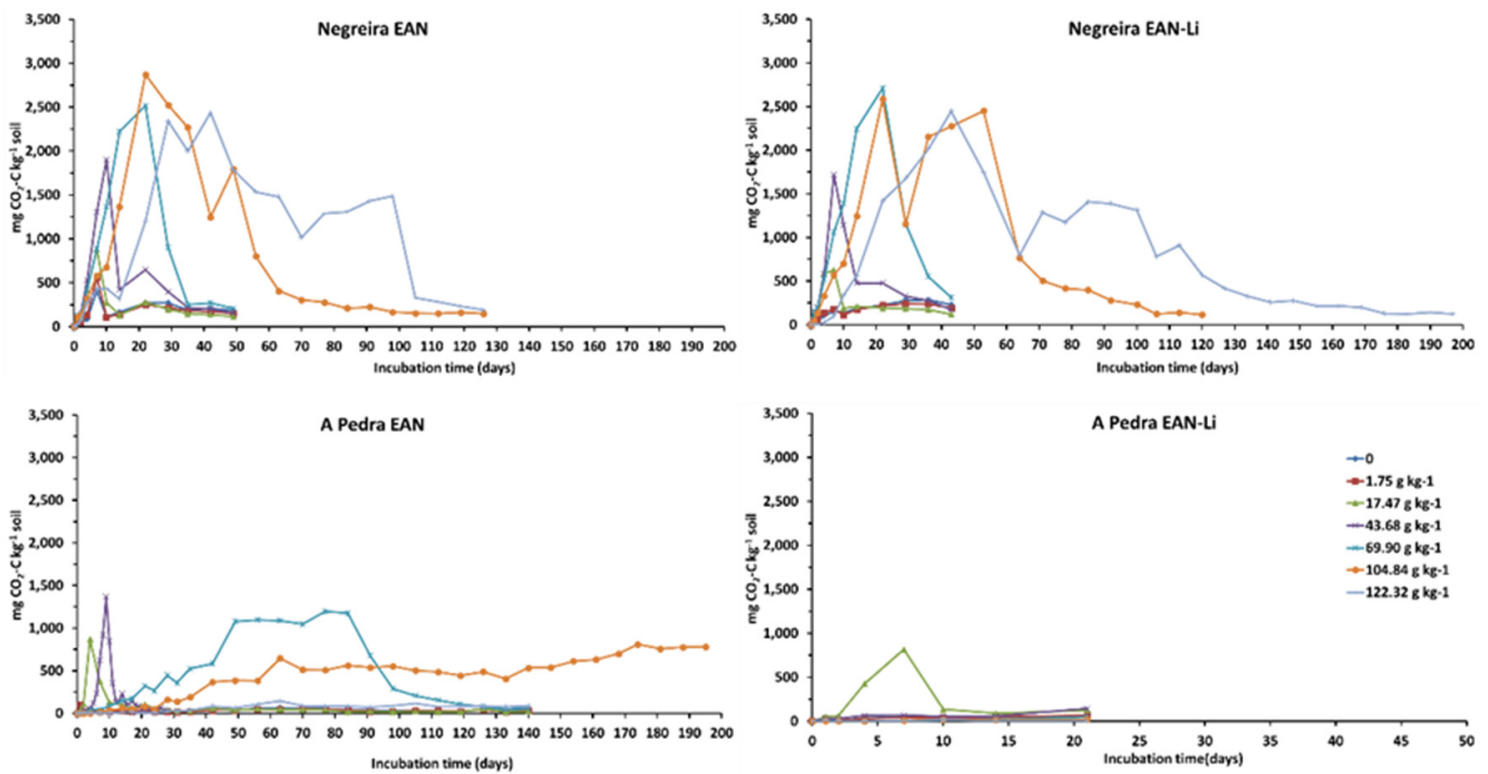

Figure 2. Kinetics of basal respiration in the un-spiked Negreira (left) and A Pedra (right) soils and in the same soils spiked with different amounts of ethylammonium nitrate (EAN) alone (above) or mixed with lithium nitrate salt (EAN-Li) (below). Note that the limits of $\mathrm{Y}$ and $\mathrm{X}$ axes in A Pedra soil spiked with EAN-Li are lower than in the other cases.

The delay in the peak of $\mathrm{CO}_{2}$ emission observed in this study in Negreira and A Pedra soils spiked with EAN and EAN-Li is consistent with the delay observed in heat emission detected by microcalorimetry in the same soils spiked with EAN and EAN-Al [19], with a lag in the increase in microbial activity after glucose addition to these IL-spiked soils. A similar lag period has also been observed in soils spiked with other ILs, such as 1,3 dimethylimidazolium dimethylphosphate [20]. The lag probably reflects the time that the soil microbial communities need to adapt to the new conditions due to the larger amounts of new substrates added with the EAN and the EAN-Li, and therefore the time that these microorganisms need before they start to take advantage of the new substrates available. One possible explanation for this lag is that a shift occurred in the microbial populations as a consequence of addition of large amounts of $\mathrm{C}$ and $\mathrm{N}$ with EAN and EAN-Li (Table 3 ), which caused a large increase in the total $\mathrm{C}$ and $\mathrm{N}$ contents of both soils; however, given the much higher amount of $\mathrm{N}$ than of $\mathrm{C}$ added to the soils, there was a large decrease in the $\mathrm{C} / \mathrm{N}$ ratio in the EAN and EAN-Li spiked soils (Table 3) reflecting an imbalance in the amounts of these elements in the soils. It is possible that the unequal $\mathrm{C}$ and $\mathrm{N}$ contents of the soils spiked with EAN and with EAN-Li caused a shift in soil microbial populations to a fungi-dominated community. Unfortunately, the high amounts of $\mathrm{C}$ and $\mathrm{N}$ present in in the EAN and EAN-Li-spiked soils prevented determination of microbial biomass, 
which relies on measurement of the $\mathrm{C}$ and $\mathrm{N}$ released after killing the microorganisms present in the soil [21], and therefore we were unable to test this hypothesis. However, shortly after the start of the incubation period (10-26 days), spots of fungi were visible on the surface of the A Pedra soil spiked with EAN (at concentrations of $69.90 \mathrm{~g} \mathrm{~kg}^{-1}$ and above). The surface area covered by fungi increased gradually over time and the fungi also gradually appeared in the soils spiked with lower amounts of EAN $\left(43.68 \mathrm{~g} \mathrm{~kg}^{-1}\right)$. The short incubation time for the A Pedra soil spiked with EAN-Li prevented the appearance of fungi, but fungi were also visible on the surface of the Negreira soil spiked with the highest amounts of both EAN and EAN-Li. The fungi were first observed in the A Pedra soil, and were apparently more abundant than in the Negreira soil, which may reflect the relatively stronger impact of the addition of new substrates to the soil with the lower organic matter content. Fungi were only observed on the surface of the soils spiked with the highest amounts of EAN or EAN-Li, probably because fungal growth was not sufficient to be appreciable by the naked eye in the soils spiked with the lowest amounts of the compounds. Future studies will focus on testing this hypothesis by analysing the composition and structure of microbial populations in IL-spiked soils and using molecular methods to quantify the fungal and bacterial populations.

Table 3. Amounts of $\mathrm{C}$ and $\mathrm{N}$ added with the EAN and EAN-Li to the soils and the resulting total $\mathrm{C}$ and $\mathrm{N}$ contents of the spiked soils, as estimated by the sum of the initial $\mathrm{C}$ and $\mathrm{N}$ contents of the soils plus the amount added with the ILs and $\mathrm{pH}$ of un-spiked and spiked soils at the end of the incubation period.

\begin{tabular}{|c|c|c|c|c|c|c|c|}
\hline \multirow[t]{2}{*}{ Soil } & IL Applied & C Added & N Added & est. tC & Estimated $\mathrm{tN}$ & est. $\mathrm{C} / \mathrm{N}$ & \multirow{2}{*}{$\begin{array}{c}\mathrm{pH} \\
\mathrm{KCl}\end{array}$} \\
\hline & \multicolumn{3}{|c|}{---------g kg-1 soil------------- } & \multicolumn{3}{|c|}{---------- \% ----------- } & \\
\hline \multirow[t]{7}{*}{ Negreira } & 0 & 0 & 0 & 12.43 & 0.65 & 19 & 3.14 \\
\hline & 1.75 & 0.387 & 0.453 & 12.47 & 0.70 & 18 & 3.15 \\
\hline & 17.47 & 3.880 & 4.528 & 12.82 & 1.08 & 12 & 3.15 \\
\hline & 43.68 & 9.699 & 11.321 & 13.40 & 1.78 & 8 & 3.16 \\
\hline & 69.90 & 15.519 & 18.114 & 13.98 & 2.46 & 6 & 3.15 \\
\hline & 104.84 & 23.278 & 27.170 & 14.76 & 3.37 & 4 & 3.13 \\
\hline & 122.32 & 27.157 & 31.699 & 15.15 & 3.87 & 4 & 3.11 \\
\hline \multirow[t]{8}{*}{ A Pedra } & 0 & 0 & 0 & 2.17 & 0.21 & 10 & 3.74 \\
\hline & 1.75 & 0.387 & 0.453 & 2.21 & 0.26 & 9 & 3.73 \\
\hline & 17.47 & 3.880 & 4.528 & 2.56 & 0.64 & 4 & 3.60 \\
\hline & 43.68 & 9.699 & 11.321 & 3.14 & 1.34 & 2 & 3.62 \\
\hline & 69.90 & 15.519 & 18.114 & 3.72 & 2.02 & 2 & 3.68 \\
\hline & 104.84 & 23.278 & 27.170 & 4.50 & 2.93 & 2 & 3.56 \\
\hline & 122.32 & 27.157 & 31.699 & 4.89 & 3.38 & 1 & 3.62 \\
\hline & 122.32 & 27.157 & 31.699 & 4.89 & 3.38 & 1 & 3.62 \\
\hline
\end{tabular}

The lower organic matter content of the A Pedra soil lead to a greater imbalance in the $\mathrm{C}$ and $\mathrm{N}$ contents than in the Negreira soil (Table 3). This may explain why different amounts of the $\mathrm{C}$ added were consumed by both soils during microbial respiration (Table 4). Thus, in the Negreira soil the percentage of $\mathrm{CO}_{2}$ emitted during the incubation (after subtracting the $\mathrm{CO}_{2}$ emitted by the control soil) relative to the amount of $\mathrm{C}$ added with EAN and EAN-Li increased gradually with the amount of IL and was similar in EAN and in EAN-Li spiked soils. Thus, the percentage of $C$ added that was mineralised (emitted as $\mathrm{CO}_{2}$ ) ranged from 21 and $23 \%$ in the soil spiked with $17.47 \mathrm{~g} \mathrm{~kg}^{-1}$ of EAN and EAN-Li, respectively, to 73 and $76 \%$ in the soil spiked with the highest amount of EAN and EAN$\mathrm{Li}$, respectively. However, in the A Pedra soil these amounts were much lower (Table 4), especially in the soil spiked with EAN-Li, while in the soil spiked with $17.47 \mathrm{~g} \mathrm{~kg}^{-1}$ of IL a large amount of the $C$ added was mineralised. However, despite the increasingly higher proportion of $\mathrm{C}$ added that was mineralised in the Negreira soil with increasing doses of EAN and EAN-Li, the rates of mineralisation, calculated both by weight of soil and by amount of total C, were remarkably different (Table 4). 
Table 4. Percentage of $\mathrm{C}$ added that was emitted by the soils as $\mathrm{CO}_{2}-\mathrm{C}$ during the incubation, rate of $\mathrm{CO}_{2}-\mathrm{C}_{\text {emission and rate of }}$ $\mathrm{CO}_{2}-\mathrm{C}$ emission per unit of $\mathrm{C}$ for the un-spiked soils and the soils spiked with different amounts of EAN or EAN-Li.

\begin{tabular}{|c|c|c|c|c|c|}
\hline Soil & IL Applied & Days & $\begin{array}{c}\mathrm{CO}_{2}-\mathrm{C} \text { Emitted/C Added } \\
\%\end{array}$ & $\begin{array}{c}\text { Rate } \mathrm{CO}_{2}-\mathrm{C} \text { Emission } \\
\text { mg CO} \mathrm{CO}_{2}-\mathrm{C} \mathrm{kg}^{-1} \mathrm{~d}^{-1}\end{array}$ & $\begin{array}{l}\text { Rate } \mathrm{CO}_{2}-\mathrm{C} / \mathrm{Ct} \\
\mathrm{CO}_{2}-\mathrm{C} \mathrm{g}^{-1} \mathrm{C} \mathrm{d}^{-1}\end{array}$ \\
\hline Negreira & 0 & 49 & --- & 40.3 & 0.324 \\
\hline \multirow[t]{6}{*}{ EAN } & 1.75 & 49 & 8 & 41.0 & 0.322 \\
\hline & 17.47 & 49 & 21 & 56.7 & 0.442 \\
\hline & 43.68 & 49 & 42 & 123.3 & 0.920 \\
\hline & 69.90 & 49 & 47 & 189.9 & 1.358 \\
\hline & 104.84 & 126 & 65 & 134.0 & 0.908 \\
\hline & 122.32 & 126 & 73 & 173.6 & 1.146 \\
\hline Negreira & 0 & 43 & --- & 39.2 & 0.315 \\
\hline \multirow[t]{6}{*}{ EAN-Li } & 1.75 & 43 & 0 & 37.3 & 0.299 \\
\hline & 17.47 & 43 & 23 & 60.3 & 0.470 \\
\hline & 43.68 & 43 & 40 & 122.6 & 0.915 \\
\hline & 69.90 & 43 & 55 & 233.2 & 1.668 \\
\hline & 104.84 & 120 & 63 & 138.6 & 0.939 \\
\hline & 122.32 & 197 & 76 & 113.6 & 0.750 \\
\hline A Pedra & 0 & 140 & --- & 6.4 & 0.294 \\
\hline \multirow[t]{6}{*}{ EAN } & 1.75 & 140 & 0 & 6.2 & 0.280 \\
\hline & 17.47 & 140 & 39 & 17.2 & 0.672 \\
\hline & 43.68 & 140 & 53 & 43.2 & 1.376 \\
\hline & 69.90 & 140 & 67 & 80.8 & 2.172 \\
\hline & 104.84 & 140 & 55 & 70.2 & 1.56 \\
\hline & 122.32 & 140 & 2 & 10.4 & 0.213 \\
\hline A Pedra & 0 & 21 & --- & 12.2 & 0.562 \\
\hline \multirow[t]{6}{*}{ EAN-Li } & 1.75 & 21 & 3 & 12.8 & 0.579 \\
\hline & 17.47 & 21 & 37 & 81.0 & 3.164 \\
\hline & 43.68 & 21 & 2 & 21.3 & 0.678 \\
\hline & 69.90 & 21 & 0 & 4.6 & 0.124 \\
\hline & 104.84 & 21 & 0 & 3.3 & 0.073 \\
\hline & 122.32 & 21 & 0 & 2.1 & 0.041 \\
\hline
\end{tabular}

In all cases, the mineralisation rate tended to increase with the amount of IL added, up to $69.90 \mathrm{~g} \mathrm{~kg}^{-1}$, and thereafter tended to decrease, although it always remained much higher than in the control soil. The mineralisation rate followed similar behaviour in the A Pedra soil spiked with EAN, although in this case there was a very large decrease in the mineralisation rate after addition of the largest amounts of EAN (Table 4). Both in the A Pedra and Negreira soils spiked with either EAN or EAN-Li, the rate of mineralisation in the soil spiked with the lowest amount of IL was the same as in the control soil, irrespective of whether the rate per weight of soil or per total $\mathrm{C}$ was considered. The difference between the rate of mineralisation and the proportion of $C$ added to the soil that is mineralised must be explored further, as currently we do not have an explanation for this finding, although it may be related to the unequal amounts of $\mathrm{C}$ and $\mathrm{N}$ and the decrease in $\mathrm{C} / \mathrm{N}$ ratio with the amount of IL added.

Finally, it is also remarkable that lithium did not affect soil respiration in the Negreira soil, as the basal soil respiration in the Negreira soil spiked with EAN-Li was similar to that in the Negreira soil spiked with the pure EAN. However, in the A Pedra soil spiked with EAN-Li, all of the parameters investigated (soil respiration, kinetics of $\mathrm{CO}_{2}$ emission, rate of $\mathrm{CO}_{2}$ emission per weight of soil and per total amount of $\mathrm{C}$ ) were strongly affected by lithium, which greatly reduced the soil respiration and modified the related parameters. The difference in the effect of lithium on soil respiration in the Negreira soil (no effect) 
and the A Pedra soil (strong effect) suggests that lithium is fixed by soil organic matter [21], thus mitigating any possible impact on soil respiration in the Negreira soil. Although clays can also fix lithium [22], the clay content was the same in both soils (Table 2) and the clay was probably of the same type, as both soils were developed over granite rock. The lithiumfixing capacity of both soils should therefore be similar, thus indicating that the different impact of lithium on the soils can probably be explained by the organic matter content.

\section{Conclusions}

The application of pure ethylammonium nitrate (EAN) or EAN mixed with lithium nitrate salt (EAN-Li) to soils strongly affected soil respiration, which generally increased and was accompanied by a delay in the appearance of the peak of $\mathrm{CO}_{2}$ emission characteristic of soils incubated under optimal temperature and moisture conditions. The soil organic matter content strongly affected the impact of EAN and EAN-Li on soil respiration, mitigating the changes in the $\mathrm{C}$ and $\mathrm{N}$ contents brought about by the addition of these new substrates to the soils and thus the negative effect of lithium. The findings suggest that the differences in the amounts of $\mathrm{C}$ and $\mathrm{N}$ added to the soil with the two compounds cause a shift to fungi-dominated microbial communities, although this hypothesis remains to be tested.

Author Contributions: Conceptualization, methodology, formal analysis, writing-original draft preparation and writing - review and editing, T.S., M.E.P., O.R., J.J.P., J.S. and C.T.-C.; funding acquisition, J.S. and C.T.-C. All authors have read and agreed to the published version of the manuscript.

Funding: This research was financially supported by the Spanish MICINN through project CGL2015-66857-C2-1-R co-financed by the ERDF, and by the Xunta de Galicia through the RCG projects IN607A 2017/6, ED431C2019/07 and ED431C 2020/10, and the Galician Network project ED431D 2017/06. J. J. Parajó is grateful for funding support from the I2C postdoctoral Program of the Xunta de Galicia. E. Priano is grateful for funding support from Enhancing Mobility between Latin-American and Caribbean countries and Europe Program (Argentina-España, 2018).

Data Availability Statement: The data supporting the findings presented here are available from the corresponding author on request.

Acknowledgments: The authors acknowledge A. Iglesias Tojo and D. Portela for technical support.

Conflicts of Interest: The authors declare no conflict of interest. The funders had no role in the design of the study; in the collection, analyses, or interpretation of data; in the writing of the manuscript, or in the decision to publish the results.

\section{References}

1. Pérez de los Ríos, A.; Hernández, F.J. Ionic Liquids in Separation Technology; Elsevier: Amsterdam, The Netherlands, 2014.

2. Bello, D.; Muiño, F.; García-Carballal, S.; Salgado, J.; Trasar-Cepeda, C. Modification of the method to determine dehydrogenase activity in soils spiked with 1-butyl-3-methylimidazolium tetrafluoroborate [BMIM][BF4]. In Proceedings of the 20th International Electronic Conference Synthetic Organic Chemistry, Sciforum Electronic Conference Series; Seijas, J.A., Vázquez Tato, M.P., Eds.; MDPI: Basel, Switzerland, 2016a; Volume 20, pp. f001. 1-9.

3. Bello, D.; García-Carballal, S.; Muiño, F.; Salgado, J.; Trasar-Cepeda, C.; A pH-adjusted method to measure urease activity in soils spiked with tetrafluoroborate 1-butyl-3-methylimidazolium tetrafluoroborate [BMIM][BF4]. In Proceedings of the 20th International Electronic Conference Synthetic Organic Chemistry, Sciforum Electronic Conference Series; Seijas, J.A., Vázquez Tato, M.P., Eds.; MDPI: Basel, Switzerland, 2016b; Volume 20, pp. f007 1-7.

4. Ucha, C.; Reyes, O.; Salgado, J.; Trasar-Cepeda, C.; Bello, D. Toxic effects of [BMIM][BF4] on early growth of Eucalyptus globulus Labill. In Proceedings of the 21th International Electronic Conference Synthetic Organic Chemistry, Sciforum Electronic Conference Series, Seijas, J.A., Vázquez Tato, M.P., Eds.; MDPI: Basel, Switzerland, 2017; Volume 21, pp. f006-1/f006-8.

5. Garlitz, J.A.; Summers, C.A.; Flowers, R.A.; Borgstahl, G.E. Ethylammonium nitrate: A protein crystallization reagent. Acta Crystallogr. Sect. D Biol. Crystallogr. 1999, 55, 2037-2038.

6. Jaganathan, M.; Ramakrishnan, C.; Velmurugan, D.; Dhathathreyan, A. Understanding ethylammonium nitrate stabilized cytochrome c-Molecular dynamics and experimental approach. J. Mol. Struct. 2015, 1081, 334-341. 
7. Salgado, J.; Parajó, J.J.; Villanueva, M.; Rodríguez, J.R.; Cabeza, O.; Varela, L.M. Liquid range of ionic liquid-Metal salt mixtures for electrochemical applications. J. Chem. Thermodyn. 2019, 134, 164-174.

8. Fitzpatrick, E.A. Soils: Their Formation, Classification and Distribution; Longman: London, UK, 1980.

9. Cihacek, L.J.; Anderson, W.L.; Barak, P.W. Methods for Assessing Soil Quality; Doran, J.W., Jones, A.J., Eds.; Soil Science Society of America-American Society of Agronomy: Madison, WI, USA, 1996; pp. 9-24.

10. Visser, S.; Parkinson, D. Soil biological criteria as indicators of soil quality: Soil microorganisms. Am. J. Altwern. Agric. 1992, 7, 33-37.

11. Doran, J.W.; Parkin, T.B. Defining and Assessing Soil Quality. In Defining Soil Quality for a Sustainable Environment; Doran, J.W., Coleman, D.C., Bezdicek, D.F., Stewart, B.A., Eds.; Soil Science Society of America-American Society of Agronomy: Madison, WI, USA, 1994; pp. 3-21.

12. Dick, R.P.; Soil enzyme activities as integrative indicators. In Biological Indicators of Soil Health; Pankhurst, C.E., Doube, B.M., Gupta, V.V.S.R., Eds.; CAB International: Wallingford, UK, 1997; pp. 121-156.

13. Bello, D.; Trasar-Cepeda, C.; Leirós, M.C.; Gil-Sotres, F. Modification of enzymatic activity in soils of contrasting pH contaminated with 2,4-dichlorophenol and 2,4,5-trichlorophenol. Soil Biol. Biochem. 2013, 56, 80-86.

14. ISSS Working Group RB. World Reference Base for Soil Resource. Introduction, 1st ed.; Acco: Leuven, Belgium, 1998.

15. Bello, D.; Trasar-Cepeda, C.; Leirós, M.C.; Gil-Sotres, F.; Evaluation of different tests for the diagnosis of soil contamination by 2,4,5-trichlorophenol (2,4,5-TCP). Environ. Pollut. 2008, 156, 611-617.

16. Bello, D.; Nogueira, J.; Salgado, J.; Reyes, O.; Trasar-Cepeda, C. Germination and development of Lepidium sativum L. and Eucalyptus globulus Labill. In two different soils spiked with the ionic liquid [C1C1Im][DMP]. Fressenius Environ. Bull. 2019, 28, 924-929.

17. Guitián-Ojea, F.; Carballas-Fernández, T. Técnicas de análisis de suelos. Pico Sacro Editorial, Santiago de Compostela, Spain, 1976.

18. USDA (United States Departament of Agriculture), Soil Survey Manual; Agriculture Handbook 18; United States Department of Agriculture: Washington, DC, USA, 1951.

19. Ucha, C.; Reyes, O.; Trasar-Cepeda, C.; Salgado, J.; Parajó, J.J. Ecotoxicological Evaluation of Ethylammonium Nitrate and Aluminium Salt Mixture. Chem. Proc. 2021, 3, 1.

20. Sixto, T.; Ucha, C.; Trasar-Cepeda, C.; Reyes, O., Salgado, J.; Effects of three ionic liquids on microbial activity of an organic soil. Microcalorimetric study. In Proceedings of the 22th International Electronic Conference Synthetic Organic Chemistry; Seijas, J.A., Vázquez Tato, M.P., Eds.; MDPI: Basel, Switzerland, 2018; 5p.

21. Kot, F.S. On the rubidium and lithium content and availability in the sub-arid south-eastern Mediterranean: Potential health implications. Environ Geochem. Health 2018, 40, 1841-1851.

22. Hoyer, M.; Kummer, N.-A.; Merkel, B.; Sorption of Lithium, on Bentonite, Kaolin and Zeolite. Geosciences 2015, 5, 127-140. 